\title{
ANALISIS POLA SEBARAN KEJADIAN LONGSORLAHAN DI KECAMATAN SOMAGEDE DENGAN SISTEM INFORMASI GEOGRAFIS
}

\author{
A.W. Nirwansyah ${ }^{a}$, M.Utami $^{b}$, Suwarno $^{c}$, T.Hidayatullah $^{d}$ \\ ${ }^{a}$ Lab.Geologi \& Penginderaan Jauh Univ. Muhammadiyah Purwokerto, Indonesia, email: anang.gisser@gmail.com \\ ${ }^{b}$ Univ. Muhammadiyah Purwokerto, Indonesia, email: meilina632@gmail.com, \\ ${ }^{c}$ Univ. Muhammadiyah Purwokerto, Indonesia, email: pemangkulongsor@yahoo.co.id \\ ${ }^{d}$ Badan Informasi Geospasial, Indonesia, email: taufiktmg@gmail.com
}

\begin{abstract}
Article Info;
Abstract: Landslide is part of the earth forming mechanism that is dynamic. This research is

Received:

9 March 2015 aimed at identifying the spatial pattern of landslide occurrences in Somagede District based on

in revised form: field survey and GIS as the tool of analysis. The survey has focused on occurrences and footprint that can be identified. Based on the field survey, there are 39 points of landslide 13 March 2015 occurrences laid in seven villages with steep and very steep slope categories. Meanwhile, the average neighbor analysis shows the clustering pattern of the landslide in Somagede, where the value of Nearest Neighbor Ratio is 0.768496 . This hypothesis is supported by the z-score

Accepted:

25 March 2015 value of -2.77 and $p$-value of 0.0057 that are statistically accepted. (C) 2015 GJGP UNDIP. All rights reserved.
\end{abstract}

Available Online:

30 April 2015

Keywords:

landslide, spatial

distribution, GIS

Info Artikel;
Diterima:
9 Maret 2015
Hasil Revisi :
13 Maret 2015
Disetujui:
25 Maret 2015
Publikasi On-Line:
30 April 2015

\begin{abstract}
Abstrak: Longsorlahan adalah bagian dari mekanisme pembentukan bumi yang secara dinamis berubah. Tujuan penelitian ini adalah mengidentifikasi pola sebaran kejadian longsor yang terjadi di Kecamatan Somagede dengan menggunakan hasil survei lapangan dan memanfaatkan SIG sebagai alat analisis. Kegiatan survey difokuskan pada pencarian bentuk ataupun jejak longsoran yang teridentifikasi di lapangan dan memasukkan data koordinat. Pengambilan sampel diambil secara insidental dengan mendasarkan pada hasil temuan di lapangan. Dari hasil lapangan ditemukan 39 titik sampel longsor yang tersebar di 7 desa yang didominasi pada kelas kemiringan lereng curam dan sangat curam. Hasil analisis tetangga terdekat menunjukkan pola mengelompok (clustering) dari kejadian longsor yang ada di Somagede, dengan nilai indeks ketetanggaan sebesar 0,768496. Hipotesis ini didukung dengan nilai z-score sebesar -2.77 dan p-value sebesar 0,0057 yang menyatakan secara statistik hipotesis ini diterima. (C) 2015 GJGP UNDIP. All rights reserved.
\end{abstract}

Kata kunci:

longsorlahan, pola

sebaran, SIG

\section{PENDAHULUAN}

Longsorlahan merupakan bagian dari mekanisme pembentukan relief bumi yang secara dinamis mengalami perubahan. Kontribusi tenaga eksogen dan endogen dalam hal ini menjadi faktor utama yang berlangsung secara kontinyu. Thornbury (1954) menyatakan bahwa proses endogen berupa diastropisme (orogenesis dan epirogenesis) dan vulkanisme. Proses tersebut biasanya bersinergi terhadap proses eksogen yang bersifat destruktif yang dalam hal ini terdiri atas pelapukan, erosi, transportasi, pengendapan, dan denudasi. Aktivitas proses eksogen dipengaruhi oleh kondisi lokal dan aktivitas manusia 
(Zektser, Marker, Ridgway, Rogachevskaya, \& Vartanyan, 2007). Kondisi demikian berlangsung di seluruh permukaan bumi termasuk di Indonesia.

Tanah longsor pada bulan Desember 2014 terjadi sebanyak 111 kali, jauh lebih banyak dibandingkan banjir (86 kejadian). Kejadian bencana tanah longsor tersebar di 12 provinsi, dengan frekuensi terbanyak berturut-turut terjadi di Jawa Tengah, Jawa Barat, dan Jawa Timur (BNPB, 2014). Daerah perbukitan dan berlereng merupakan daerah yang berpotensi bahaya longsor, dan khususnya di Jawa Tengah kejadian longsor sangat banyak terjadi akibat kondisi topografinya sebagai daerah pegunungan dan perbukitan yang memiliki lereng yang curam.

Kabupaten Banyumas merupakan wilayah dengan topografi pegunungan dan perbukitan dengan potensi bahaya longsor yang cukup besar. BPBD Kabupaten Banyumas (2012) menyatakan kejadian bencana longsor di Kecamatan Somagede pada tahun 2012 - 2014 pernah tercatat pada tanggal 30 November 2012 dengan 2 kejadian longsor besar, yaitu di Desa Kanding RT 03/02 Kecamatan Somagede yang menimpa rumah warga, kemudian kejadian bencana longsor pada tanggal 4 Desember 2012 di Desa Kemawi terjadi tanah longsor yang menimpa beberapa rumah warga namun tidak ada korban jiwa. Pada tahun 2013 BPBD Kabupaten Banyumas juga melaporkan beberapa kejadian yang terjadi di Somagede khususnya kejadian longsor yang menyebabkan kerusakan ataupun korban jiwa. Berdasarkan laporan kejadian bencana BPBD Kabupaten Banyumas tercatat kejadian longsor di Kecamatan Somagede pada tanggal 3 juli 2013 di Desa Klinting RT 06/01 yang mengakibatkan rumah warga rusak sedang dan lantai rumah induk ambles karena rumah warga berdiri di atas tanah yang labil di tepi jurang yang cukup dalam \pm 10 meter. Kejadian bencana longsor pada tanggal 12 Juli 2013 di Desa Grumbul Wlahar Desa Somagede Kecamatan Somagede, saat itu terjadi hujan lebat mengakibatkan sungai yang berada di Desa Somagede banjir, sehubungan dengan kejadian tersebut menimbulkan tebing yang berada di belakang bangunan masjid mengalami longsor sehingga rusak parah (BPBD Kabupaten Banyumas, 2013).

Kajian mengenai longsor dan pemetaan kejadian longsor seringkali menemukan pola dan keterkaitan antara bentuk lereng dan penutup lahan. Beberapa penelitian longsorlahan dengan memanfaatkan SIG dilakukan termasuk Suhendar (1994); Mubekti (2011); Suwarno \& Sutomo (2007); Grozavu et al. (2013). Beberapa penelitian lain juga memanfaatkan metode kuantitatif yang dikombinasikan dengan pemetaan diantaranya dilakukan oleh Oh et al. (2010) dan juga memanfaatkan kedalaman air tanah sebagai dasar penentuan kerawanan longsor yang dilakukan oleh Rahmawati et al. (2012). Penelitian yang dilakukan oleh Dragicevic et al. (2015) yang mengembangkan metode untuk longsor di daerah perkotaan dan memanfaatkan analisis multi kriteria dalam GIS. Pemanfaatan beberapa parameter diantaranya digital elevation model (DEM), jaringan drainase dan jaringan jalan dilakukan untuk menghasilkan peta kerawanan longsor di daerah perkotaan.

Khusus untuk pasca kejadian longsor, pemetaan kejadian tentunya juga dilakukan untuk melihat distribusi spasial termasuk pola sebaran yang memungkinkan pengambil kebijakan untuk menentukan tingkat potensi bahaya longsor di daerah tersebut. Pemanfaatan SIG dalam hal ini bisa dikembangkan sebagai alat bantu analisis ketetanggan yang akan digunakan sebagai acuan dalam menentukan wilayah mana yang memiliki kontribusi terhadap kejadian longsor paling besar ataupun rendah.

\section{DATA DAN METODE}

\subsection{Kejadian longsor}

Penelitian ini dilakukan dengan menggunakan data hasil survei kejadian longsor yang dilaksanakan pada Kecamatan Somagede. Kecamatan Somagede secara administratif merupakan salah satu kecamatan di Kabupaten Banyumas yang secara astronomis terletak pada posisi $7^{\circ} 28^{\prime} 45^{\prime \prime}-7^{\circ} 33^{\prime}$ 25" LS dan $109^{\circ} 17^{\prime} 55^{\prime \prime}-109^{\circ} 23^{\prime} 45^{\prime \prime}$ BT. Kecamatan Somagede mempunyai luas wilayah 40,11 km². Kecamatan Somagede berbatasan dengan tiga Kecamatan dan satu Kabupaten yaitu;

- Sebelah utara berbatasan dengan Kecamatan Kalibagor

- Sebelah selatan berbatasan dengan Kecamatan Kemranjen

- Sebelah barat berbatasan dengan Kecamatan Banyumas

- Sebelah timur berbatasan dengan Kabupaten Banjarnegara

Kecamatan Somagede terdiri atas 9 desa dengan luas antara 3,05 $\mathrm{km}^{2}$ sampai 9,68 $\mathrm{km}^{2}$ dan total luas wilayah Kecamatan Somagede adalah $40,11 \mathrm{~km}^{2}$. Kondisi topografi Kecamatan didominasi oleh wilayah perbukitan di bagian timur. Kondisi ketinggian lahan di Kecamatan Somagede mempunyai 
relief bervariasi berupa dataran rendah, dataran tinggi dan perbukitan. Daerah dataran rendah ini menempati wilayah bagian utara memanjang ke arah barat-timur berupa daerah pertanian, daerah dataran tinggi dan perbukitan menempati sebagian wilayah bagian tengah dan utara dengan ketinggian mencapai 250-1500 mdpl (lihat Gambar 1).

Gambar 1. Peta elevasi Kecamatan Somagede (Peta Rupabumi Indonesia, 2001)

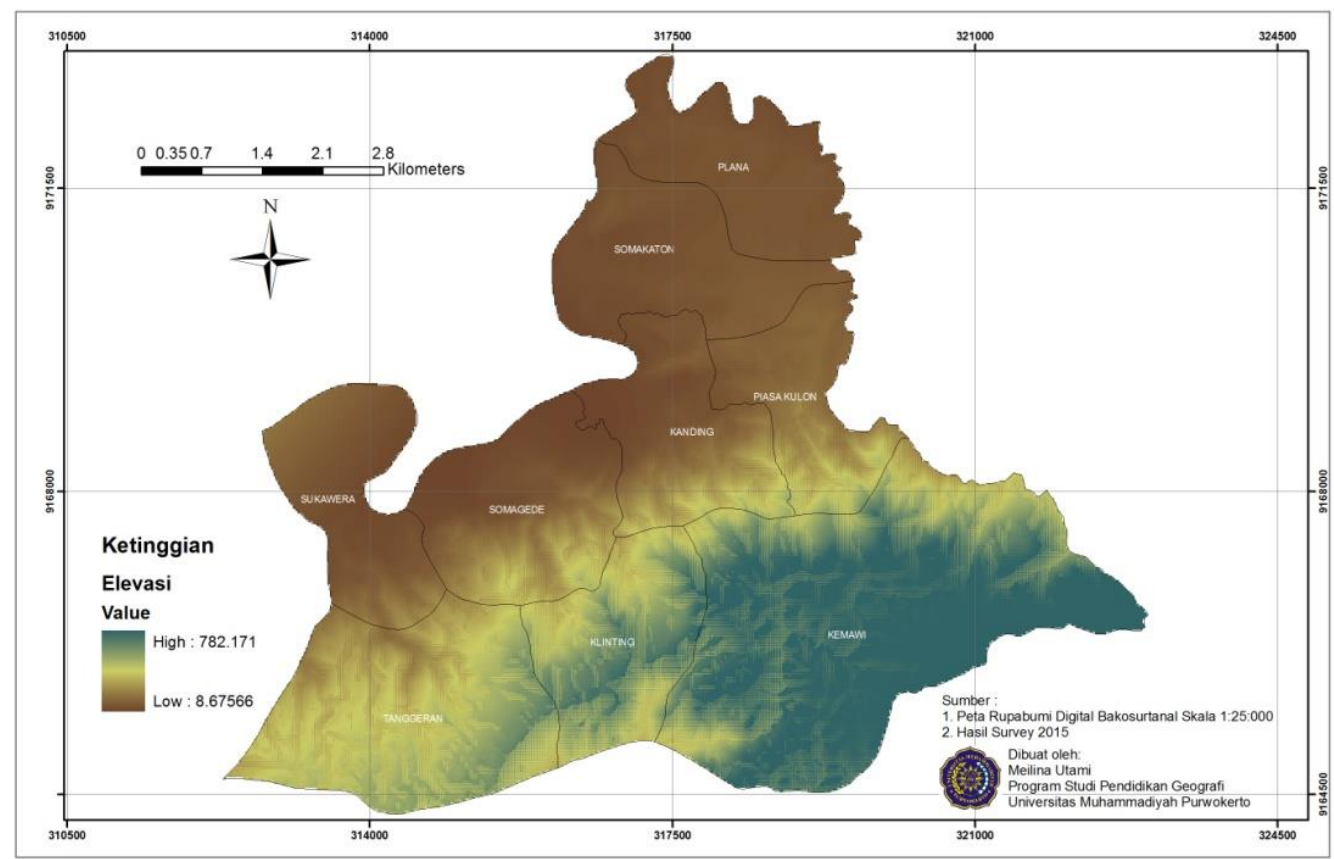

\subsection{Pengumpulan data}

Data kuantitatif yang dihasilkan berupa sebaran koordinat $x, y$ dari kejadian longsor di seluruh wilayah pengamatan. Survei dilakukan secara terstruktur dengan menggunakan GPS dan lokasi longsor ditentukan dengan incidental sampling serta hasil informasi dari penduduk. Data laporan kejadian longsor dari BPBD Kabupaten Banyumas juga digunakan sebagai panduan penentuan titik longsor. Perangkat yang digunakan untuk pengolahan data hasil survei yakni menggunakan ArcGIS 9.3 dan SPSS 17 sebagai pengolah data statistik. Penggunaan citra satelit resolusi tinggi sebagai bahan intepretasi adalah citra GoogleEarth dengan otomasi rektifikasi menggunakan SAS Planet. Peta kemiringan lereng dihasilkan dari olah data kontur peta Rupa Bumi Indonesia Skala 1:25.000. Kriteria kemiringan lereng yang digunakan adalah sebagaimana digunakan lihat Tabel 1.

Tabel 1. Klasifikasi lereng dan satuan morfologinya (Van Zuidam, 1983)

\begin{tabular}{ccl}
\hline Kelerengan (\%) & Klasifikasi & \multicolumn{1}{c}{ Satuan morfologi } \\
\hline $\mathbf{0 - 8}$ & Datar & Dataran \\
$\mathbf{> 8 - 1 5}$ & Landai & Perbukitan berelief halus \\
$\mathbf{> 1 5 - 2 5}$ & Agak Curam & Perbukitan berelief sedang \\
$\mathbf{> 2 5 - 4 5}$ & Curam & Perbukitan berelief kasar \\
$>\mathbf{4 5}$ & Sangat Curam & Perbukitan berelief sangat kasar \\
\hline
\end{tabular}

\subsection{Populasi dan sampel}

Populasi yang digunakan dalam penelitian ini adalah seluruh wilayah Kecamatan Somagede dengan lima kelas lereng, sedangkan teknik pengambilan sampel yakni menggunakan insidental sampling yakni teknik penentuan sampel berdasarkan lokasi kejadian longsor yang ditemukan pada tiap lerengnya. Sampel yang dimaksud yaitu kejadian longsor di daerah Kecamatan Somagede 
Kabupaten Banyumas. Survey yang dilaksanakan menemukan sejumlah 39 titik kejadian longsor yang tersebar di 7 desa pada wilayah Kecamatan Somagede.

\subsection{Metode analisis}

Metode analisis kerapatan adalah memanfaatkan analisis tetangga terdekat merupakan salah satu analisis yang digunakan untuk menjelaskan pola persebaran dari titik-titik lokasi dengan mempertimbangkan jarak, index kedekatan, z-score, dan p-value(ESRI, 2013). Z-score dan p-value adalah ukuran signifikansi statistik yang menunjukkan distribusi data acak. Indeks tetangga terdekat akan digunakan sebagai rasio dari jarak rata-rata data dengan jarak rata-rata standar.Indeks tetangga terdekat dinyatakan sebagai rasio jarak diamati dibagi dengan jarak yang diharapkan. Jarak yang diharapkan adalah jarak rata-rata antara tetangga dalam distribusi acak hipotetis. Jika indeks kurang dari 1, pola menunjukkan pengelompokan; jika indeks lebih besar dari 1, tren ke arah dispersi atau persaingan (ESRI,2009) (lihat Gambar 2).

Gambar 2. Ilustrasi average nearest neighbor (ESRI,2009)

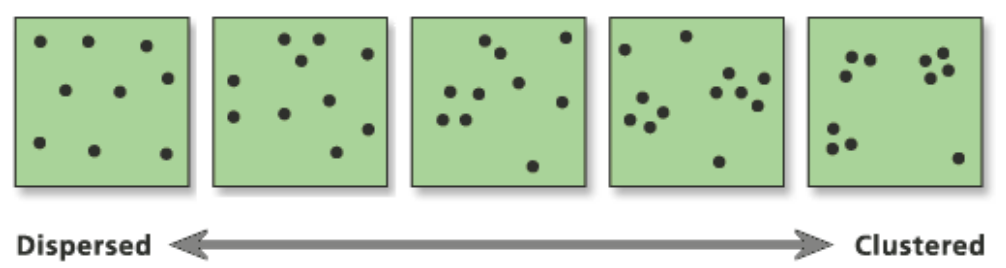

Penggunaan formula analisis tetangga terdekat dalam hal ini menggunakan formula yang statistik average nearest neighbor (ANN) sebagai berikut

$$
\begin{gathered}
A N N=\frac{\bar{D}_{0}}{\bar{D}_{E}} \\
\bar{D}_{O}=\frac{\sum_{\mathrm{i}=1}^{\mathrm{m}} \mathrm{d}_{\mathrm{i}}}{\mathrm{m}} \\
\bar{D}_{E}=\frac{0.5}{\sqrt{\frac{\mathrm{m}}{\mathrm{A}}}}
\end{gathered}
$$

Dimana $\mathrm{D}_{\mathrm{o}}$ adalah jarak rata-rata yang diamati antara setiap fitur dan tetangga terdekat mereka, sedangkan $\mathrm{D}_{\mathrm{E}}$ adalah jarak rata-rata yangdiharapkan untuk fitur dengan pola acak. Madalah jumlah kejadian, dan A mewakili luas wilayah. Nilai ANN dinyatakan dengan ANN=1 berarti berpola acak (random); ANN < 1 berarti mengelompok (clustered); dan ANN > 1 berarti terpencar (dispersed). Identifikasi pola distribusi kejadian longsor di Kecamatan Somagede dilakukan dengan perhitungan statistik dalam lingkungan SIG berdasarkan hasil survey dan inventarisasi kejadian longsor yang diperoleh dari masyarakat. secara rinci proses pelaksanaan penelitian dilakukan berdasarkan tahapan yang ditunjukkan pada diagram alir penelitian pada Gambar 3 sebagai berikut. 
Gambar 3. Diagram alir penelitian

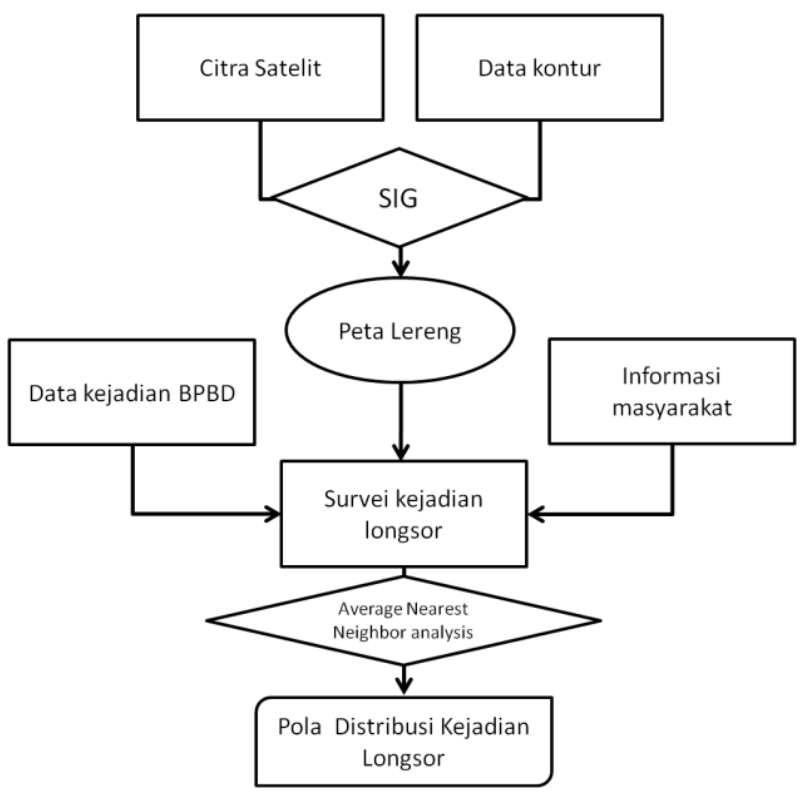

\section{HASIL DAN PEMBAHASAN}

3.1 Kejadian longsor

Hasil survey yang dilaksanakan menunjukkan jumlah kejadian longsor yang ada di Kecamatan Somagede sebanyak 39 kejadian yang tersebar di di 7 desa yaitu Desa Sokawera, Desa Somagede, Desa Kanding, Desa Piasa Kulon, Desa Klinting, Desa Tanggeran dan Desa Kemawi. Sebagian besar wilayah di Somagede merupakan daerah perbukitan dengan kemiringan lereng $20-40 \%$ (kategori curam) dan sebagian yang lain merupakan daerah datar dengan potensi longsor yang rendah (lihat Tabel 2).

Tabel 2. Kondisi kemiringan lereng di Kecamatan Somagede (Hasil analisis, 2015)

\begin{tabular}{|c|c|c|c|c|}
\hline \multirow{2}{*}{ No. } & \multirow{2}{*}{$\begin{array}{l}\text { Kemiringan } \\
\text { lereng (\%) }\end{array}$} & \multirow[b]{2}{*}{ Kategori } & \multicolumn{2}{|c|}{ Luas } \\
\hline & & & $\mathrm{Ha}$ & $\%$ \\
\hline 1. & $0-8$ & Datar & $11.052,54$ & 26,83 \\
\hline 2. & $8-15$ & Landai & $2.231,46$ & 5,42 \\
\hline 3. & $15-25$ & Agak curam & $1.362,02$ & 3,31 \\
\hline 4. & $25-45$ & Curam & $18.429,10$ & 44,74 \\
\hline 5. & $>45$ & Sangat curam & $8.111,97$ & 19,70 \\
\hline \multicolumn{3}{|c|}{ Jumlah } & $41.187,09$ & 100,00 \\
\hline
\end{tabular}

Tabel diatas menunjukkan distribusi kelas lereng I dengan kategori datar dan kelas kemiringan lereng kurang dari $8 \%$ terdapat 2 titik kejadian longsor yaitu di tebing jalan sepanjang jalan desa, yang terletak di dataran sampai perbukitanberbatuan berupa endapan lanau dan pasir yang merupakan endapan alluvial, pasir anggota endapan undak, konglomerat tufa dan breksi andesit. Kelas lereng II termasuk kategori Landai dengan kemiringan lereng 8 sampai $15 \%$ tidak terdapat kejadian longsor yang terletak di dataran alluvial berbatuan lanau, pasir, kerikil, dan kerakal. Kelas lereng III termasuk kategori Agak curam dengan kemiringan lereng 16 sampai 25\% terdapat 5 titik kejadian longsorlahan sebagian besar terjadi pada tebing jalan yang merupakan tanah hasil pelapukan, terletak di perbukitan struktural berbatuan berupa pasir anggota endapan undak, konglomerat, tufa, dan breksi andesit. Kelas lereng IV termasuk kategori Curam dengan kemiringan lereng 26 sampai $45 \%$ terdapat 31 titik kejadian longsorlahan sebagian besar berupa guguran tanah atau longsoran tebing jalan dengan kemiringan yang hampir tegak, kemudian tanah yang cukup tebal dan curah hujan yang tinggi, terletak di perbukitan berbatuan breksi andesit yang telah mengalami pelapukan yang intensif dan membentuk 
tanah pelapukan yang sangat tebal ( $5-10$ meter). Kelas lereng $\mathrm{V}$ termasuk kategori sangat curam dengan kemiringan lereng lebih dari $45 \%$ terdapat 22 titik kejadian longsorlahan terjadi akibat pelapukan breksi andesit berupa material lempung pasiran, yang terletak di lereng perbukitan dan punggungan bukit berbatuan breksi andesit, konglomerat, dan tufa yang merupakan bagian dari Formasi halang.

Kejadian longsor di Kecamatan Somagede tersebar di beberapa kelas kemiringan lereng. Sejumlah kejadian terkait dengan kondisi lereng setempat yang didominasi oleh kelas kemiringan lereng curam. Tingkat pelapukan intensif yang didukung dengan curah hujan yang tinggi menjadi faktor penyebab terjadinya longsor. Secara merata wilayah Somagede yang merupakan wilayah perkebunan semi teknis dengan sistem drainase yang buruk menyebabkan peningkatan gaya berat dalam pemindahan material erosi dari permukaan tanah. Aliran permukaan yang meningkat akan menyebabkan penurunan fisik tanah khususnya pada tingkat kemiringan lereng $30-40 \%$ yang didominasi oleh tanah bersolum dangkal, tingkat kandungan organik rendah, serta porositas tanah yang rendah.

Kejadian longsor pada daerah penelitian terbanyak merupakan gerakan tanah tipe debris avalanche, merupakan gerakan tanah tipe aliran cepat pada suatu aliran yang meluncur dari debris batuan pada celah yang sempit dan berlereng terjal (Gambar 4a). Disisi yang lain kejadian longsor juga dikategorikan pada kategori longsor translasi yakni pemindahan material pada bidang gelincir yang lurus (Gambar 4b).

Gambar 4. a) debris avalanche pada lereng sangat curam, b) longsor tipe translasi pada lereng kategori curam (Survei primer, 2014)

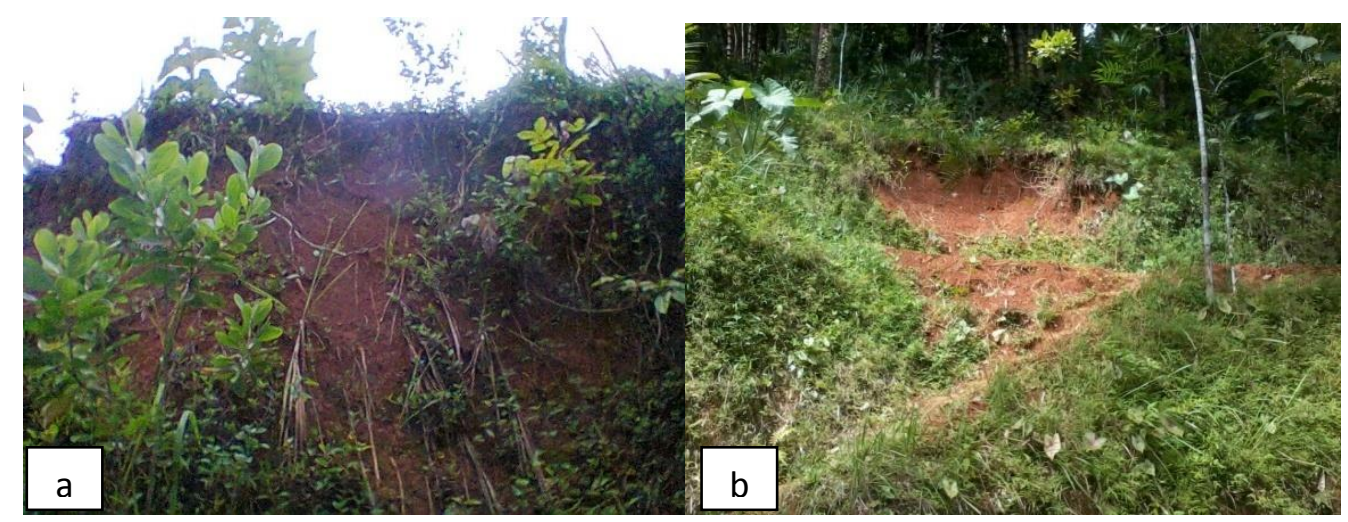

Merujuk pada Peraturan Menteri Pekerjaan Umum Nomor 22/PRT/M/2007 dinyatakan bahwa daerah berpotensi longsorlahan adalah kawasan yang rawan terhadap bencana longsor dengan kondisi medandan kondisi geologi yang sangat peka terhadap gangguan luar, baik yang bersifat alami maupun aktivitas manusia sebagai faktor pemicu gerakan tanah, sehingga berpotensi terjadinya longsor (Kementerian Pekerjaan Umum, 2007). Hasil survei menunjukkan kondisi longsor yang terjadi di Kecamatan Somagede didominasi pada kemiringan lereng sangat curam yakni sebanyak 15 (38,5\%). Lereng dengan kategori curam juga berkontribusi cukup besar pada kejadian longsorlahan di Kecamatan Somagede. Sebanyak $11(28,2 \%)$ kejadian longsor terjadi pada wilayah tersebut, yang banyak didominasi oleh perkebunan dan pekarangan penduduk. Tidak banyak kejadian longsor pada lerengi datar dan landai karena secara teori kemiringan lereng merupakan faktor pendukung kejadian longsor di suatu wilayah. Suwarno (2014) dalam penelitiannya di Kecamatan Pekuncen Kabupaten Banyumas menyatakan bahwa terdapat hubungan positif antara kemiringan lereng terhadap kejadian longsor. Karakter longsorlahan tipe translasi juga mendominasi kejadian longsor di Kecamatan Somagede yang memiliki karakter topografi yang relatif sama dengan Kecamatan Pekuncen, meskipun demikian masih perlu dilakukan kajian untuk mengidentifikasi karakteristik longsorlahan di Kecamatan Somagede. Berikut ini kejadian longsorlahan pada masing-masing kelas kemiringan lereng sebagaimana ditunjukkan pada Tabel 3. 
Tabel 3. Kejadian longsorlahan pada tiap kelas kemiringan lereng (Hasil analisis, 2015)

\begin{tabular}{ccccr}
\hline \multirow{2}{*}{ No } & \multirow{2}{*}{ Kemiringan lereng (\%) } & Kategori & \multicolumn{3}{c}{ Kejadian Longsor } \\
\cline { 3 - 5 } $\mathbf{1}$ & $0-8$ & Datar & 3 & \% \\
$\mathbf{2}$ & $8-15$ & Landai & 2 & 7.7 \\
$\mathbf{3}$ & $15-25$ & Agakcuram & 8 & 5.1 \\
$\mathbf{4}$ & $25-45$ & Curam & 11 & 20.5 \\
$\mathbf{5}$ & $>45$ & Sangatcuram & 15 & 28.2 \\
& Jumlah & & 39 & 38.5 \\
\hline
\end{tabular}

3.2 Pola distribusi kejadian longsor

Analisis pola sebaran kejadian longsor menggunakan analisis tetangga terdekat menunjukkan nilai rata-rata z-skor dan nilai-p dalam SIG. Penggunaan software ArcGIS 9.3 dalam hal ini difokuskan pada nilai tetangga terdekat yang terdapat pada Spatial Statistic toolbox. Perhitungan statistik berdasarkan hasil titik sebaran lokasi longsorlahan di Kecamatan Somagede akan menjadi masukan data titik yang akan dihitung indeks kedekatannya. Besaran nilai z-skor akan terkait dengannilai-p, pada kondisi distribusi normal. Hal tersebut secara statistik juga berkaitan dengan standar deviasi probabilitas yang memungkinkan signifikasi dan kepercayaan pada nilai z-skor dan nilai-p (ESRI, 2009).

Hasil survei yang dilakukan menunjukkan sebaran kejadian longsor di Kecamatan Somagede yang tersebar di 7 desa. Beberapa titik longsor terkonsentrasi pada satu tempat yang berkemiringan lereng curam termasuk di Desa Klinting, dan Desa Kemawi yang masuk dalam zona rawan bahaya longsor menurut BPBD Kabupaten Banyumas. Di wilayah lain, khususnya pada lereng landai dan datar dengan kemiringan 0-8\% hanya ditemui 3 kejadian longsor diantaranya di Desa Somagede, Desa Piasa Kulon dan Desa Kanding. Distribusi kejadian longsor di Kecamatan Somagede dapat dilihat pada Gambar 5 berikut ini.

Gambar 5. Peta Kejadian Longsor di Kecamatan Somagede (Hasil Analisis, 2015)

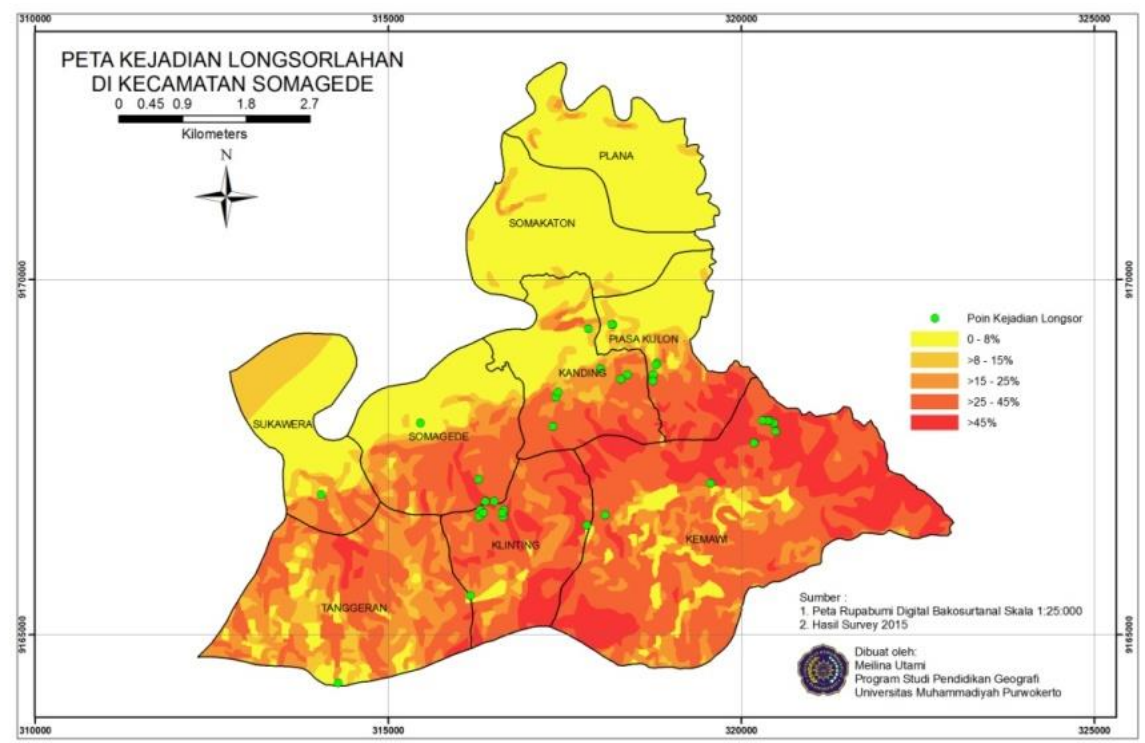

Perhitungan analisis ketetanggaan menunjukkan angka rasio 0,768496 yang artinya menunjukkan pengelompokan kejadian longsor pada wilayah-wilayah tertentu.Pola pengelompokan ini dihasilkan dari nilai observed mean distance sebesar 272,39 dan nilai expected mean distance sebesar 354.44. hasil perhitungan statistik menunjukkan nilai z-score sebesar -2,77 dan p-value sebesar 0,0057 yang menunjukkan signifikansi terhadap hipotesis rasio ketetanggaan tersebut. Pola sebaran kejadian longsor dengan 39 titik kejadian dengan perhitungan ANN telah dihasilkan angka sebagai berikut: 


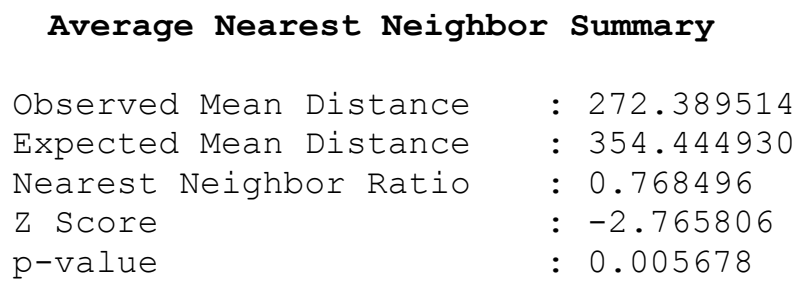

Pembuktian kebenaran apakah sebaran kejadian longsor tersebut mengelompok atau tidak dapatdigunakan uji signifikansi yang tuliskan sebagai berikut.

i. $H_{0}$ : tidak terdapat pola kejadian longsor yang mengelompok

$H_{1}$ : terdapat pola kejadian longsor yang mengelompok

ii. Tingkat signifikansi $\alpha$

iii. Daerah kritis

$H_{0}$ ditolak jika $Z_{\text {-score }}>Z_{\alpha / 2}=2,58$ atau

$$
Z_{\text {-score }}<Z_{\alpha / 2}=-2,58
$$

dengan $Z_{\alpha / 2}$ diperoleh dari tabel normal

iv. Statistik uji

Berdasarkan software ArcGis 9.3, diperoleh hasil output pada gambar xx dengan $Z$. scoresebesar -2.77

v. Kesimpulan

Berdasarkan perhitungan $Z_{\text {-score }}$ sebesar $-2.77<Z_{\alpha / 2}=-2,58$ maka $H_{0}$ ditolak artinya terdapat kejadian longsor dengan pola mengelompok.

Gambar 6. Hasil Average Nearest Neighbor Distance (ANN) pada ArcGIS 9.3 (Hasil analisis, 2015)

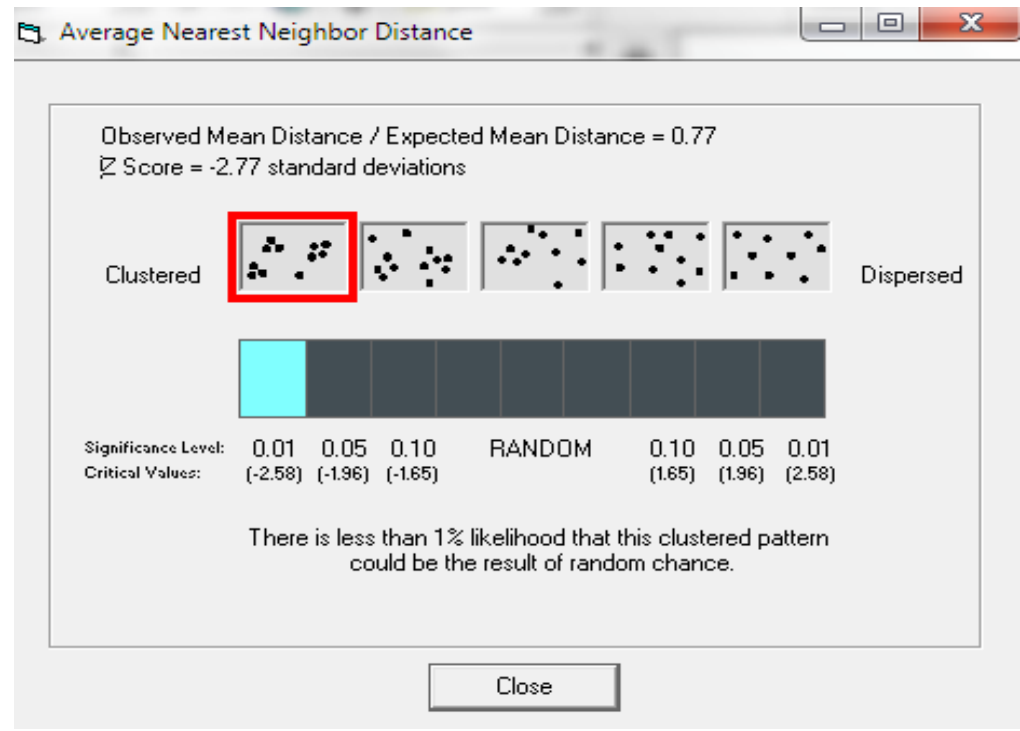

Hasil identifikasi pola kejadian longsor tersebut sekiranya terkait dengan kondisi lahan yang ada di Kecamatan Somagede. Penggunaan lahan permukiman yang saat ini mulai merambah daerah dengan kemiringan lereng curam termasuk pembukaan lahan untuk perkebunan menjadi salah satu faktor terjadinya pola mengelompok dalam kejadian longsor. Gangguan dari luar terhadap kondisi medan dan solum tanah yang cukup tebal khususnya di wilayah sekitar permukiman yang cenderung mengelompok dapat berimbas pada peningkatan potensi kejadian longsor di wilayah Kecamatan Somagede. Beberapa desa khususnya Desa Klinting dan Kemawi merupakan wilayah yang berpotensi mengalami kejadian longsor seiring dengan peningkatan kebutuhan akan permukiman dan pembukaan lahan untuk areal perkebunan oleh masyarakat yang cukup masif. Area budidaya yang memerlukan jumlah air yang cukup banyak khususnya padi dapat mendorong terjadinya penjenuhan lapisan tanah. Kontinuitas kejadian ini akan menyebabkan peningkatan beban tanah pada wilayah berlereng curam. 
Kondisi tersebut akan menyebabkan percepatan kejadian longsorlahan khususnya pada lapisan bawah yang berbatuan tufa dengan karakter kedap air dan bertindak sebagai bidang gelincir.Menurut ahli dari Lembaga IImu Pengetahuan Indonesia (LIPI), ada dua faktor penting yang menyebabkan terjadinya bencana tanah longsor yaitu derajat kemiringan lahan yang curam dan terjal serta aliran air (BNPB, 2014).

\section{KESIMPULAN}

4.1 Simpulan

Pola kejadian longsorlahan di Kecamatan Somagede Kabupaten Banyumas adalah mengelompok (clustered) pada tingkat kemiringan lereng curam hingga sangat curam dan terdistribusi pada 7 desa. Kondisi ketebalan solum tanah yang tebal dan didorong oleh curah hujan yang sangat tinggi menjadi penyebab peningkatan bahaya longsor di Kecamatan Somagede.

\subsection{Saran}

Pengelolaan lahan untuk mencegah terjadinya bahaya longsorlahan perlu dilakukan pada Kecamatan Somagede dengan beberapa teknik konservasi lahan. Mengurangi penebangan pohon yang tidak terkendali dan tidak terencana termasuk penanaman tanaman keras perlu dilakukan agar meningkatkan kemampuan mengikat tanah oleh akar. Disisi lain masyarakat perlu mengurangi penanaman pohon besar dengan akar dangkal agar mengurangi risiko roboh saat terjadi longsor.

\section{DAFTAR PUSTAKA}

BNPB. (2014). Info Bencana. Jakarta: Badan Nasional Penanggulangan Bencana.

BPBD Kabupaten Banyumas. (2012). Data Bencana 2012. Purwokerto: BPBD Kabupaten Banyumas.

BPBD Kabupaten Banyumas. (2013). Data Bencana 2013. Purwokerto: BPBD Kabupaten Banyumas.

Dragicevic, S., Terence, L., \& Shivanand, B. (2015). GIS-based multicriteria evaluation with multiscale analysis to characterize urban landslide susceptibility in data-scarce environments. Habitat International, 45(2), 114-125. doi:10.1016/j.habitatint.2014.06.031

ESRI. (2009). ArcGIS Desktop Help. Retrieved March 03, 2015, from http://resources.esri.com/arcgisdesktop/

Grozavu, A., Plescan, S., Patriche, C. V., Muarguarint, M. C., \& Rocsca, B. (2013). Landslide susceptibility assessment: GIS application to a complex mountainous environment. In The Carpathians: Integrating Nature and Society Towards Sustainability (pp. 31-44). Springer.

Kementerian Pekerjaan Umum. Permen PU 22/PRT/M/2007 Tentang Pedoman Penataan Ruang Kawasan Rawan Bencana Longsor (2007). Jakarta, Indonesia: Kementerian Pekerjaan Umum.

Mubekti, M. (2011). Mitigasi Daerah Rawan Tanah Longsor Menggunakan Teknik Pemodelan Sistem Informasi Geografis; Studi Kasus: Kecamatan Sumedang Utara dan Sumedang Selatan. Jurnal Teknologi Lingkungan, 9(2).

Oh, H.-J., Lee, S., \& Soedradjat, G. M. (2010). Quantitative landslide susceptibility mapping at Pemalang area, Indonesia. Environmental Earth Sciences, 60(6), 1317-1328.

Rahmawati, N., Nirwansyah, A. W., \& Mardiatno, D. (2012). Groundwater Table and Landslide Vulnerability In Various Landforms In The Prambanan District (Bokoharjo, Sumberharjo, Wukirharjo, and Sambirejo Sub Districts). Geopolitics, History and International Relations, 4(2), 260.

Suhendar, R. (1994). Terrain MappingApproach for Slope Instability Hazard andRisk Assessment Using Remote SensingTechniques and GIS; A Case Study of NorthEast Bandung and Lembang, West Java, Indonesia. Twente.

Suwarno, \& Sutomo. (2007). Metode Mitigasi Longsorlahan di Kecamatan Gumelar Kabupaten Banyumas Provinsi Jawa Tengah. Forum Geografi, 21(1), 93-104.

Thornbury, W. D. (1954). Principles of Geomorphology. Soil Science, 78(2), 157.

Van Zuidam, R. A. (1983). Guide to Geomorphologic Aerial Photographic Interpretation and Mapping. International Institute for Geo-Information Science and Earth Observation, Enschede, The Netherlands, 325.

Zektser, I. S., Marker, B., Ridgway, J., Rogachevskaya, L., \& Vartanyan, G. (2007). Geology and Ecosystems. Springer Science \& Business Media. 